\title{
As TIC em atividades de linguagem plástica - uma experiência na formação inicial de professores realizada em e-learning
}

\section{Lúcia Grave Magueta}

Escola Superior de Educação e Ciências Sociais, CI\&DEI, Politécnico de Leiria, Portugal, lucia.magueta@ipleiria.pt

\section{Resumo}

Este artigo apresenta um estudo sobre uma experiência de formação realizada no contexto da formação inicial de professores. Num momento em que é fundamental desenvolver competências digitais foi proporcionado aos estudantes do curso de licenciatura em Educação Básica formação no âmbito do uso das TIC em atividades de linguagem plástica, com aplicação a contextos educativos para crianças dos 3 aos 10 anos. Foi seguida uma metodologia de caráter qualitativo que se estruturou em três momentos: (1) Aplicação de um questionário de diagnóstico, para levantamento de dados acerca dos conhecimentos prévios dos estudantes sobre a utilização de tecnologias digitais em atividades com a linguagem plástica destinadas a crianças; (2) Abordagem prática com exploração de três ferramentas digitais acessíveis online, específicas para a criação plástica - realização de composições visuais com as ferramentas ArtBuilder, Picassohead e Jacksonpollock.org; (3) Registo reflexivo, escrito, sobre as experiências vivenciadas, com referência ao desenvolvimento de competências pedagógicas. Esta experiência decorreu inteiramente na modalidade de elearning durante um dia letivo, requerendo aos estudantes o uso de uma ferramenta de trabalho colaborativo - Padlet, para partilha de composições visuais realizadas - e a consulta de informação em vários suportes digitais. Os dados recolhidos através da aplicação do questionário e da realização do registo escrito foram tratados através da análise de conteúdo. Os resultados evidenciam que os estudantes ampliaram os seus conhecimentos sobre a utilização pedagógica das TIC, tendo realizado composições visuais representativas de um uso amplo das ferramentas sugeridas; relacionaram o uso das ferramentas com experiências de expressão plástica que se podem proporcionar às crianças em contextos diversificados; e perspetivaram propostas educativas com a exploração de uma das ferramentas sugeridas, explicitando quais seriam as oportunidades de aprendizagem com tecnologias na educação artística. 
As TIC em atividades de linguagem plástica - uma experiência na formação inicial de professores realizada em e-learning

Palavras-chave: Formação de Professores; Linguagem plástica; TIC

\section{Introdução}

No curso de licenciatura em Educação Básica da Escola Superior de Educação e Ciências Sociais (ESECS) do Politécnico de Leiria, o desenvolvimento do currículo e o cumprimento dos objetivos de formação prevê, de uma forma transversal, o desenvolvimento de competências digitais dos futuros educadores e professores e a formação no âmbito da utilização pedagógica das TIC.

O referido curso integra no seu plano de estudos a unidade curricular de Prática Pedagógica II, cuja finalidade é a iniciação à prática profissional. Numa lógica de investigação da práxis, considerámos importante estudar uma experiência formativa realizada nesta unidade curricular no ano letivo de 2019-2020 - o Seminário «As TIC enquanto recurso pedagógico: ferramentas digitais para atividades com a linguagem plástica». Neste seminário participaram 29 estudantes do $2 .^{\circ}$ ano, num momento em que estavam prestes a iniciar atividades em contextos educativos com crianças dos 3 aos 10 anos.

Este seminário de formação e o estudo das suas diferentes dimensões tiveram como objetivos: demonstrar como as TIC podem ser utilizadas em experiências de criação plástica e de desenvolvimento da literacia visual; perceber quais são as ferramentas digitais com aplicação à expressão plástica e adequadas a crianças que são conhecidas pelos professores em formação; relacionar o uso das ferramentas digitais sugeridas com as referências curriculares que existem para a Educação Pré-Escolar e 1. ${ }^{\circ}$ Ciclo do Ensino Básico; perspetivar propostas educativas envolvendo as TIC e a expressão plástica, identificando as aprendizagens das crianças. O seminário foi realizado através de metodologias de educação a distância, uma vez que se vivia globalmente um momento de confinamento devido à pandemia de COVID-19. Assim sendo, foram «desenhadas» na plataforma de e-learning do Politécnico de Leiria várias tarefas que os estudantes desenvolveram individualmente e sequencialmente, ao longo de um dia letivo. Com esta experiência os estudantes também puderam ter preparação para intervir nos contextos reais de trabalho com crianças, recorrendo a metodologias de ensino e aprendizagem a distância.

\section{Breve contextualização teórica}

Os atuais documentos curriculares para a Educação Pré-Escolar e para o $1 .^{\circ}$ Ciclo do Ensino Básico - Orientações Curriculares para a Educação Pré-Escolar e Aprendizagens Essenciais para as Artes Visuais - referem-se à utilização das tecnologias digitais na 
Educação Artística, desafiando os educadores e os professores a proporcionar às crianças/alunos experiências neste âmbito. Torna-se assim essencial que a formação de professores habilite os mesmos não só no domínio das tecnologias, mas também na sua utilização enquanto recurso pedagógico.

Atendendo ao conceito de «linguagem plástica», definido por Civit \& Colell (2004), esta tem uma gramática visual mediante a qual podemos expressar-nos e comunicar com os outros. Esta gramática é formada pelo «alfabeto visual» - composto pelo ponto, a linha, a superfície, a cor, a textura, o volume e a forma - que são as «letras» que podemos combinar para nos expressarmos. É também formada pela «sintaxe visual» - que tem em conta a medida, a proporção, o agrupamento, a estrutura, a direção, o movimento, o ritmo, o equilíbrio, a simetria, a assimetria, a harmonia e o contraste - que são as formas que temos para poder combinar as «letras» do alfabeto visual. Também para estas autoras, o uso da linguagem plástica permite gerar novos conhecimentos, desenvolver a sensibilidade e a cratividade, enriquecer a capacidade de comunicação e expressão e ampliar a forma de ver, entender e interpretar o mundo.

Ao referir-se a oportunidades de aprendizagem com tecnologias na Educação Artística, Costa et al (2012) sublinham que estas podem permitir o acesso a uma grande variedade de obras artísticas. Destacamos ainda duas das situações mencionadas, por nos parecerem pertinentes e relacionadas com o tema que abordamos no seminário: «favorecer o pensamento e a prática artística criando oportunidades que permitam a vivência e a apropriação de diferentes técnicas de produção artística com recurso às tecnologias digitais» e, também, «desenvolver a autoestima e a autoconfiança criando oportunidades que permitam a utilização das tecnologias para comunicar, dialogar e refletir sobre os processos e os constrangimentos presentes na criação artística» (pp.78-79).

Importa então perceber que ferramentas digitais existem e que possibilitam o uso da linguagem plástica, sendo o trabalho de Rodrigues (2015) uma referência nesta área. Ao preparar o seminário de formação, procurámos ferramentas de acesso livre para atividades com a linguagem plástica que pudessem ser utilizadas por crianças dos 3 aos 10 anos e identificámos as seguintes: Picassohead, ArtBuilder, Jacksonpollock.org, Weavesilk, Thisissand, Patterns of Infinity e Matisse - The Drawing Room. Tendo em conta o tempo disponível e as potencialidades formativas para os estudantes a envolver, foram selecionadas para o seminário apenas as três primeiras.

\section{Metodologia}

Tendo em conta os objetivos anteriormente apresentados, o estudo, de caráter descritivo e qualitativo, seguiu uma metodologia de estudo de caso. Considerou-se que este estudo de 
As TIC em atividades de linguagem plástica - uma experiência na formação inicial de professores realizada em e-learning

caso era do tipo «intrínseco» (Stake, 1999), pois importava compreender exclusivamente o valor formativo da experiência, sem relação com outros casos ou outras problemáticas mais abrangentes.Tal como também já foi referido, envolveu um grupo de 29 estudantes, heterogéneo em idades, género, nacionalidade e grupos de referência/ representações de identidade e, no momento em que decorreu a experiência formativa descrita neste estudo, preparava-se para realizar a formação em contextos educativos reais, com crianças entre os 3 e os 10 anos. A recolha de dados concretizou-se durante o desenvolvimento do seminário de formação realizado na plataforma de e-learning, tendo este sido estruturado em três momentos distintos. Explicitam-se em seguida as tarefas que corresponderam a cada momento:

Momento 1. Preenchimento do Questionário de Diagnóstico, composto por uma questão fechada - 1. As TIC podem ser usadas na criação plástica ou no desenvolvimento da literacia visual? - e duas questões abertas - 2. De que modo relaciona as TIC com experiências de expressão plástica? e 3. Que ferramentas digitais com aplicação à expressão plástica e adequadas a crianças conhece?.

Momento 2. Exploração de recursos relativos à apresentação das ferramentas digitais de acesso livre ArtBuilder, Picassohead e Jacksonpollock.org; Seleção de uma das ferramentas sugeridas e realização de experiências práticas de criação plástica com a mesma, construindo imagens/composições visuais; Partilha das composições visuais realizadas na «GALERIA», um mural organizado na ferramenta de trabalho colaborativo Padlet.

Momento 3. Elaboração de um registo escrito no Fórum «Reflexão» que: a) referisse as aprendizagens construídas com a experiência prática realizada; b) relacionasse o uso das ferramentas digitais sugeridas com as referências curriculares que existem para a Educação Pré-Escolar e 1. ${ }^{\circ}$ Ciclo do Ensino Básico; c) perspetivasse uma proposta educativa em que pudesse surgir a exploração de uma das ferramentas sugeridas, explicitando quais seriam as aprendizagens das crianças.

Os dados recolhidos através da aplicação do questionário (questões abertas) e da realização do registo escrito foram tratados através da análise de conteúdo.

\section{Resultados}

\subsection{Momento 1}

Os dados obtidos através do Questionário de Diagnóstico mostram, unanimemente, que os estudantes reconhecem que as TIC podem ser usadas na criação plástica ou no desenvolvimento da literacia visual. Quanto ao modo como os estudantes relacionam as 
TIC com as experiências de expressão plástica, a análise ao conteúdo das respostas permitiu-nos identificar três categorias: «Uso de ferramentas diversas para criar imagens», «Pesquisa sobre obras artísticas e os seus contextos»e «Acesso a informação sobre técnicas e materiais» (ver o Quadro 1 com excertos representativos destas categorias). No conjunto de respostas foi possível perceber que os estudantes valorizam a possibilidade de usar as TIC, embora refiram que estas experiências não devem substituir as vivências de contacto real com técnicas e materiais, salientando que a «expressão plástica está ligada ao desenvolvimento das capacidades expressivas, criativas e comunicativas das crianças».

Tabela 1 Alguns registos representativos das respostas à questão « De que modo relaciona as TIC com experiências de expressão plástica?

\begin{tabular}{|l|}
\hline Categoria «Uso de ferramentas diversas para criar imagens» \\
\hline "Permitem a exploração de diversas ferramentas» \\
"Conseguimos ter acesso a ferramentas que nos possibilitam a oportunidade de realizar desenhos, \\
pinturas, entre outros» \\
"Através de programas de desenho, pode-se ter experiências de expressão plástica» \\
"Existem aplicações ou ferramentas no telemóvel e computador que permitem criar algo relacionado \\
com expressão plástica» \\
\hline Categoria «Pesquisa sobre obras artísticas e os seus contextos » \\
"Através das TIC é possivel adquirir conhecimento artístico» \\
"Com a tecnologia digital podemos investigar, selecionar e análisar obras e após isso interagir com \\
outros sobre o que aquilo significa para nós» \\
\hline Categoria «Acesso a informação sobre técnicas e materiais » \\
\hline "(...) permitem ao aluno procurar informação que complemente o seu processo de criação» \\
«As TIC combinam com a expressão plástica, uma vez que conseguimos pesquisar e descobrir novas \\
técnicas, métodos, materiais úteis à realização de trabalhos». \\
\hline
\end{tabular}

Relativamente à questão sobre as ferramentas que conheciam, com aplicação à expressão plástica e adequadas a crianças, a menção ao programa Microsoft Paint predominou, tendo sido referida quase pela totalidade dos estudantes. No entanto, houve outros meios relacionados com a criação de imagens ou com a divulgação de obras artísticas que também foram mencionados, a saber: Tate Kids (o website do museu Tate Modern), Artpad e Sketchbook. Foram ainda referidos o Prezi, o Word e o PowerPoint, pois também possibilitam a criação de formas, seleção de cores, transformação de imagens, entre outras ações relacionadas com a linguagem visual.

\subsection{Momento 2}

Das experiências práticas com as ferramentas sugeridas, resultaram dezenas de composições visuais que foram partilhadas através da ferramenta colaborativa Padlet (disponível em https://padlet.com/luciamagueta/j6tzfotvvsz7). As diferentes composições permitiram verificar que os estudantes compreenderam o funcionamento das ferramentas 
As TIC em atividades de linguagem plástica - uma experiência na formação inicial de professores realizada em e-learning

Picassohead, ArtBuilder e Jacksonpollock.org e exploraram as diferentes possibilidades de criação que estas oferecem.

\subsection{Momento 3}

A última tarefa proposta aos estudantes referia-se à elaboração de um registo escrito, onde refletiam sobre o seminário. Para este registo era solicitado que identificassem as aprendizagens que construíram no decurso das tarefas realizadas. As respostas indicam que o seminário trouxe aos estudantes «conhecimentos sobre novas ferramentas digitais», «conhecimentos sobre elementos da linguagem plástica» e o «conhecimento de novos recursos pedagógicos» (incluido a ferramenta de trabalho colaborativo Padlet). O Quadro 2 apresenta alguns excertos dos registos, enquadrados nas respetivas categorias.

Tabela 2 Alguns registos representativos das aprendizagens construídas com a experiência prática realizada

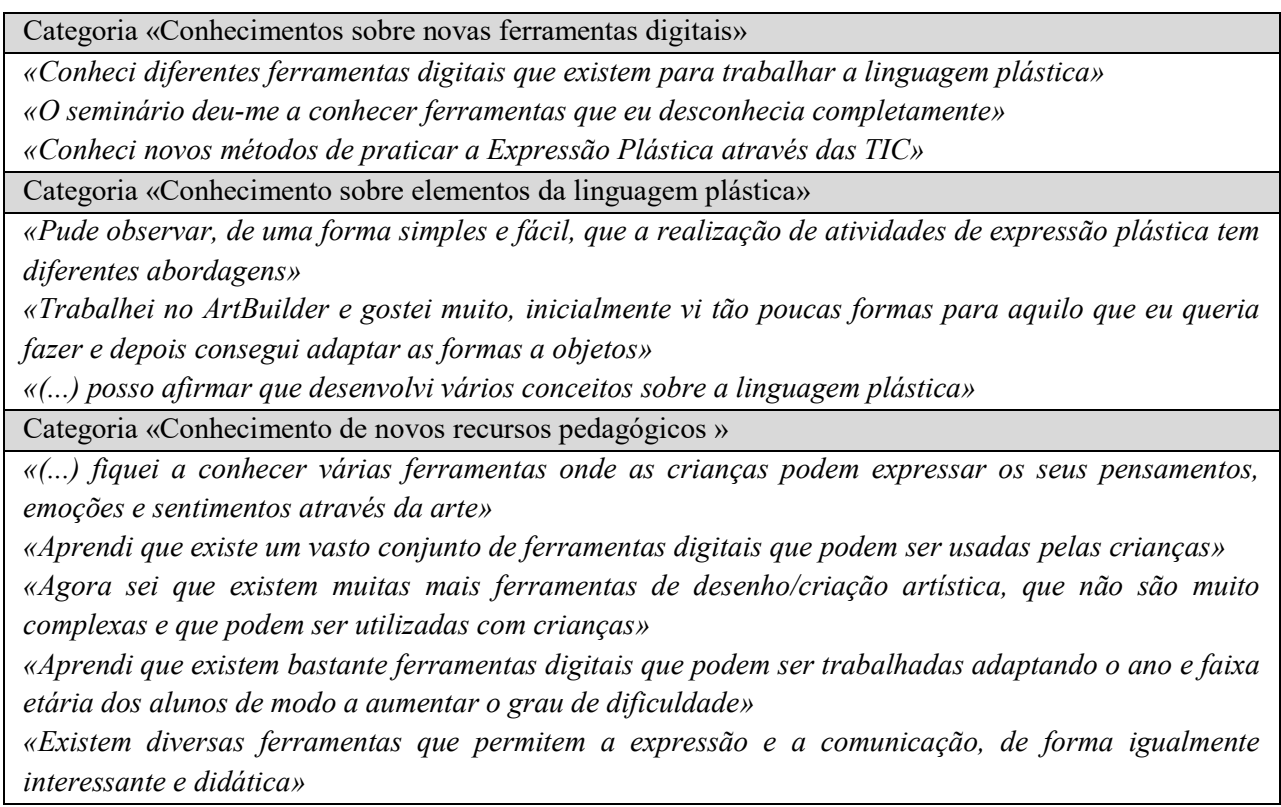

Foram muitos os estudantes que referiram ter alterado as suas conceções sobre o assunto abordado no seminário - a ideia que tinham inicialmente reduzia-se à utilização do software Paint; o seminário desocultou o que pensavam sobre experiências de criação plástica - para si, antes do seminário, estas apenas tinham sentido no contacto real com os materiais. No entanto, reconheceram que as TIC podem também proporcionar experiências de criação com os elementos da linguagem plástica, possibilitando à criança o desenvolvimento da 
criatividade e expressão, trazendo-lhe oportunidades de desenvolvimento da literacia visual. Tal como refere um dos estudantes, «percebi que existem muitas formas de desenvolver conteúdos relativos à expressão plástica sem recorrer, necessariamente, a técnicas e trabalhos manuais». Foram também frequentes as alusões às potencialidades inclusivas das ferramentas abordadas, pois «poderiam facilitar a expressão a alunos com limitações na capacidade de comunicar». Para o registo escrito foi também pedido que relacionassem as ferramentas sugeridas com referências curriculares que existem para a Educação PréEscolar e 1. ${ }^{\circ}$ Ciclo do Ensino Básico. Deste cruzamento sobressaíram as seguintes categorias: «meio para a educação estética e artística», o «desenvolvimento de atitudes», o «desenvolvimento de aptidões de coordenação» e o «desenvolvimento de competências digitais». O Quadro 3 evidencia alguns excertos dos registos efetuados pelos estudantes.

Tabela 3 Alguns registos sobre a relação entre o uso das ferramentas digitais e referências curriculares para a Educação Pré-Escolar e 1. ${ }^{\circ}$ Ciclo do Ensino Básico

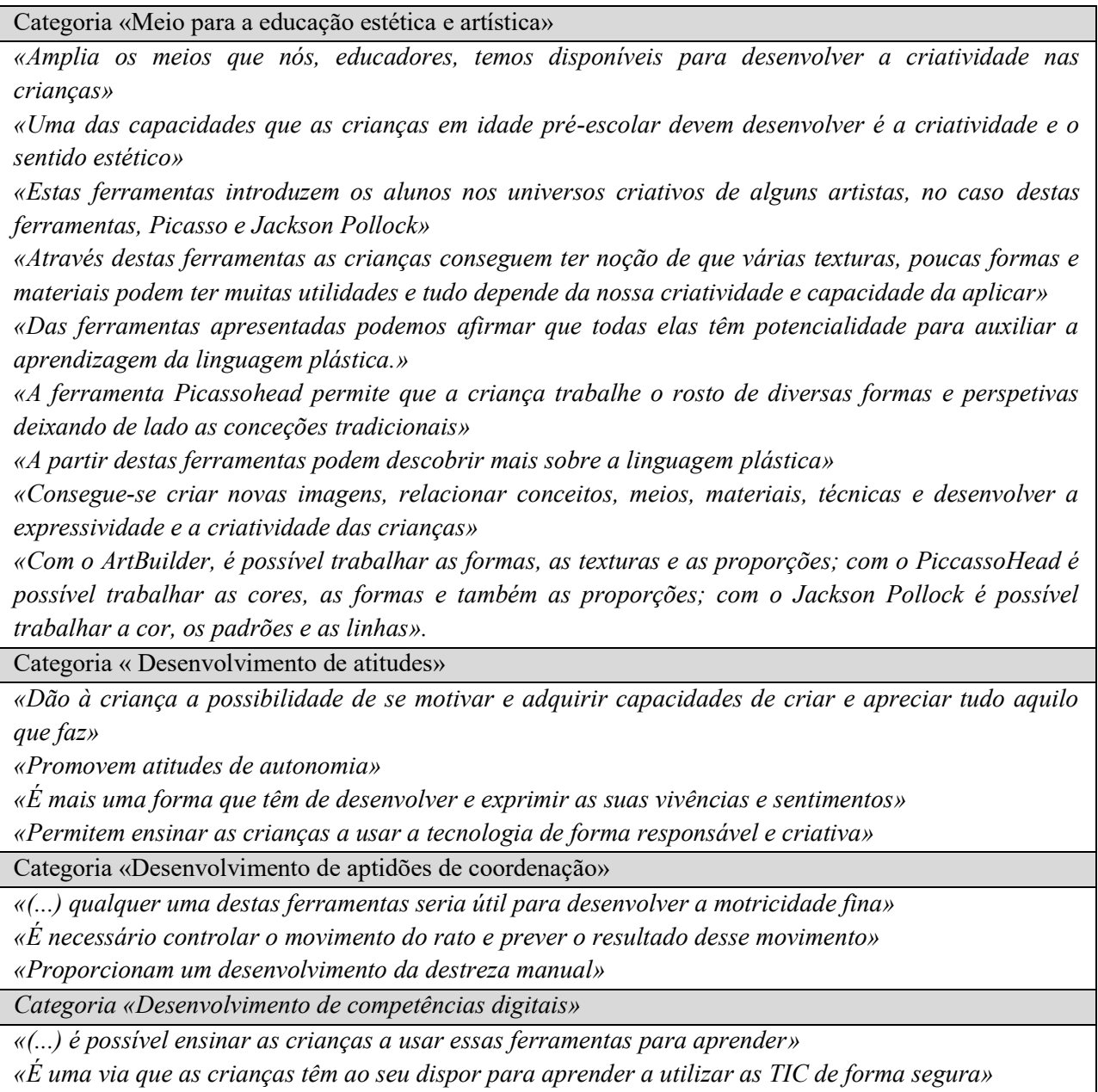


As TIC em atividades de linguagem plástica - uma experiência na formação inicial de professores realizada em e-learning

«Estas ferramentas são uma mais valia para as crianças aprenderam a trabalhar com as novas tecnologias»

«As novas tecnologias de informação e comunicação são ferramentas muito importantes de apoio às diferentes formas de expressão»

No último tópico para o registo escrito pedia-se aos estudantes que indicassem exemplos de propostas educativas que se pudessem realizar no âmbito da expressão plástica, utilizando as TIC, e as correspondentes aprendizagens a promover. Foram muito diversas as propostas, sendo apresentados alguns exemplos no Quadro 4. Estes exemplos evidenciam que os estudantes no final do seminário conseguiam perspetivar experiências de aprendizagem, com recurso às ferramentas abordadas, que possibilitavam uma exploração ampla das mesmas, em momentos de desenvolvimento da criatividade e da literacia visual. Em alguns registos foi também possível observar que as propostas tinham extensão a outras áreas do conhecimento, como a matemática (composições com formas geométricas e recurso a simetrias, por exemplo), e a outras áreas artísticas, como a música (composições com representação plástica de ritmos).

Tabela 4 Alguns exemplos de propostas educativas e de aprendizagens a promover

\begin{tabular}{|l|l|}
\hline \multicolumn{1}{|c|}{ Propostas educativas } & \multicolumn{1}{c|}{ Aprendizagens a promover } \\
\hline $\begin{array}{l}\text { Desenho do autorretrato, utilizando a ferramenta } \\
\text { Picassohead }\end{array}$ & $\begin{array}{l}\text { Forma, elementos do rosto, elementos das obras } \\
\text { de Picasso }\end{array}$ \\
\hline $\begin{array}{l}\text { Colagem representando uma situação do quotidiano, } \\
\text { utilizando a ferramenta ArtBuilder }\end{array}$ & $\begin{array}{l}\text { Caraterísticas dos materiais, noção de } \\
\text { composição, textura, forma }\end{array}$ \\
\hline $\begin{array}{l}\text { Observar obras de Picasso, relacionando-as com as } \\
\text { formas que constam na ferramenta Picassohead }\end{array}$ & $\begin{array}{l}\text { Conhecimento de obras artísticas e dos seus } \\
\text { elementos }\end{array}$ \\
\hline $\begin{array}{l}\text { Representar emoções em rostos, com recurso à } \\
\text { ferramenta Picassohead }\end{array}$ & $\begin{array}{l}\text { Forma, elementos do rosto, elementos das obras } \\
\text { de Picasso, expressividade da cor e da forma }\end{array}$ \\
\hline Criação livre, com a ferramenta Jacksonpollock.org & $\begin{array}{l}\text { Forma, cor, representação plástica do ritmo e do } \\
\text { movimento }\end{array}$ \\
\hline $\begin{array}{l}\text { Fazer composições representativas das quatro } \\
\text { estações do ano utilizando a ferramenta ArtBuilder. }\end{array}$ & Cores, textura, forma, materiais \\
\hline
\end{tabular}

\section{Conclusão}

O estudo desta experiência de formação permitiu conhecer o posicionamento dos estudantes perante a utilização pedagógica das TIC em atividades com a linguagem plástica, abrindo horizontes para essa utilização nos contextos onde iriam intervir. Permitiu igualmente construir um diagnóstico para o prosseguimento da formação ao nível da didática das expressões artísticas, especificamente no âmbito das artes visuais. Num momento em que se vivia a pandemia de COVID-19 e estando os estudantes a iniciar as primeiras experiências de prática docente com recurso a metodologias de ensino a distância, este 
momento de formação foi entendido como uma excelente oportunidade de construção da profissionalidade.

\section{Referências}

Civit, L. \& Colell, S. (2004). EducArt: intervención educativa y Expressión Plástica. Educación Social, 28, 99-118.

Costa, F. A., Rodriguez, C., Cruz, E., \& Fradão, S. (Coord.)(2012). Repensar as TIC na educação. O professor como agente transformador. Carnaxide: Santillana.

Rodrigues, J. A. B. (2015). Ferramentas Web, Web 2.0 e software livre em EVT: estudo sobre a integração de ferramentas digitais no currículo da disciplina de educação visual e tecnológica (Tese de Doutoramento em Multimédia em Educação). Universidade de Aveiro, Aveiro.

Stake, R. E. (1999). Investigación con estudio de casos. Madrid: Morata. 